\title{
CREATIVITY 4.0. EMPOWERING CREATIVITY IN THE DIGITAL ERA
}

\author{
Carmen BRUNO and Marita CANINA \\ IDEActivity Center | Design Department, Politecnico di Milano
}

\begin{abstract}
In the $21^{\text {st }}$ Century we are witnessing a radical transformation of society, primarily due to the introduction of a wealth of new devices, sensors, robots, and applications that are changing how people process information, behave, and socialise. The digital era and its technologies are having a profound impact especially on the digitally enhanced generation who are growing up with digital habits (TV, cell phones, video games, etc.) which are required to develop new competencies and skills among which human creativity is the most important one. The design education system is struggling to keep up with the demands of these new digital challenges. It has, therefore, become essential for design research to understand the impact of digital technologies on the creative process to develop an appropriate training model for the next digital generation of designers representing the actors of a near future.

The objective of this paper is to briefly present the Creativity 4.0 model framed as part of the methodology used to identify the most crucial factors that influence creativity in the digital era.

The model allows to explore some condition brought by the digital revolution that could enable or inhibit those factors and that could be of interest for the design educators' community.
\end{abstract}

Keywords: Creativity factors, digital technology, digitally enhanced generation, design education, creative design process

\section{INTRODUCTION}

In the $21^{\text {st }}$ Century we are witnessing a radical transformation of society, primarily due to the introduction of a wealth of new devices, sensors, robots, and applications that are changing how people process information, behave, socialise, and the skills they need to thrive in an increasingly complex world.

The digital era and its technologies are having a profound impact especially on the digitally enhanced generation who are growing up with digital habits (TV, cell phones, video games, etc.) and "accepts digital enhancement as an integral fact of human existence" [1]

In this digital transition, creativity has been recognised as one of the most important and distinct human skills to nurture and develop in order to manage at best the powerful collaboration between human and machine [2]. Indeed, creativity helps people in generating novel and useful ideas [3], and to get the advantage of the opportunities offered by digital technologies in any field.

The democratisation of digital technologies has opened new opportunities for people to engage in creative activities, contributing to an increased diffused manifestation of creative acts. In this digital context, creative thinking is understood as a distributed phenomenon in which digital technologies have become an integral part of the creative process [4].

The central question arising from these considerations is about how technological evolution is influencing the design and creativity abilities of the digital next generation of designers.

Indeed, designers are facing a digital revolution and need to be prepared to work in the interactive digital world in which everybody does design [5] in order to address new technological challenges achieving large-scale innovation.

The design education system is struggling to keep up with the demands of these new digital challenges [6]. It is, therefore, become essential for the design research to understand the impact of digital technologies on the creative process to develop appropriate training models for the next digital generation of designers representing the actors of a near future. 
We are all moving toward digital enhancement [1] and design educators should update their training toolbox, to train and guide the creativity skill of designers getting the advantage of the opportunities brought by digital technology.

The objective of this paper is to briefly present the Creativity 4.0 model framed as part of the methodology used to identify the most crucial factors that influence creativity in the digital era. The model allows exploring some condition brought by the digital revolution that could enable or inhibit those factors and that could be of interest for the design educators' community.

The first step, described in section 2, was to identify and collect from the broad creativity literature, the factors of creativity that have been recognised as influencing the creative design process.

The second step was to investigate the impact that the digital transition is having on the human being. The analysis of the current scenario of transition enabled us to build a Creativity 4.0 model, presented in section 3. The model was used as a sieve for the selection of the most crucial factors of creativity in the digital age and for the identification of the enabling and inhibiting condition affecting the creative process. Some examples are presented in section 4.

\section{EVOLVING CREATIVITY AND CREATIVITY FACTORS}

Creativity concept has been widely studied for a long time and many definitions have been proposed. Since it is a complex and multidimensional concept, its understanding is constantly changing according to the socio-cultural environment around us [7]. This means that the definitions of creativity evolve and fluctuate over time. Its changes need to be understood as it is a fundamental skill that can guide the human being throughout its evolution. Therefore, it is important to highlight some basic notion that will then allow to better understand the Creativity 4.0 model.

Part of the creativity literature [8] [9] is devoted to modelling and representing the creative thinking process upon which the generation of ideas is based. A process that is constituted by some mental activities that people engage in when they're creating something, from the identification of a problem to the acquisition of knowledge till the generation of an idea and its implementation.

Others, focused on the identification of the cognitive, motivational and environmental components involved in the creative thinking process [10] and how they could influence the result of the creative work.

In the last decades, with the advent of ICTs, the people and the society has started a process of transformation becoming more and more interconnected. The diffusion and the democratisation of digital technologies have had consequences on the dissemination of the creative act, generating an unprecedented number of elements in the digital realm available for creative action and reaction [4]. Understanding how the human being is co-evolving with digital technology was a fundamental step for analysing how creativity has evolved. The creativity 4.0 model arises from this analysis with the aim of providing a guide for the identification of the most crucial factors of creativity in the digital transition, and how those factors could be influenced by digital technology.

\subsection{Factors of creativity}

As mentioned before, the first step of the research was to identify and collect, from the broad creativity literature, the factors of creativity that have been recognised as influencing the steps of the creative thinking process.

Two major believes underly this work: the first one is that everyone can be creative, all persons of normal intelligence possess some ability to think creatively and to engage themselves in imaginative and innovative efforts [11]. The second one is that creativity can be trained and learn and that relies on personal attitudes, cognitive skills, individual motivations and environmental forces.

In this sense, an inspiring work has been done by Amabile (1988) [3] which identify the basic factors influencing the degree of creativity of an individual or a group of individual, throughout the problemsolving process.

33 factors have been identified. In order to facilitate their classification and analysis they have been clustered in 5 main categories according to their different nature:

- Cognitive processes and skills such as analogic and associative thinking, conceptual combination, creative invention, structured imagination. This category includes also some of the cognitive blocks occurring in the creative design process such as fixation and fear of reputation.

- Personal attitudes such as perseverance, intellectual curiosity, observation, openness to experience. 
- Technical skills such as knowledge and expertise in the domain, managing the creative process.

- Motivations which include the intrinsic factors related to personal interest and inclination.

- Socio-technical environment which includes factors related to the interaction with other people and with the technology such as the socioemotional support from others, sharing ideas with others, the access to knowledge resources, the instrumental support. These factors influence the other categories, especially motivations and cognitive processes and skills.

Several steps of iteration and refinement have been done to understand which, among those factors, can be considered as the most crucial in the digital era. The Creativity 4.0 model had a fundamental role in guiding this iteration and is described in the next section.

\section{CREATIVITY 4.0 MODEL}

A deep investigation of the literature highlights that the digital transition is radically impacting the human condition, influencing a digitally enhanced generation in profound ways on different levels. From the inner, less visible, cognitive and tacit processes that concern individuals to the outer, more evident and articulated interactions with other people and between groups of people.

The Creativity 4.0 model (Figure 1) [12], is therefore structured considering the digital transition as the ground on which the model is growing and feeding and its impact on the human being analysed according to three main levels: the cognitive level (i.e. human being learning and processing information), the individual level (i.e. human being acting in the world), the social level (i.e. human being as part of a community).

The third element of the model is indeed creativity intended as a human skill and therefore transversal to all the three levels. This subdivision allowed to consider the multiple facets of the human being involved in a creative activity.

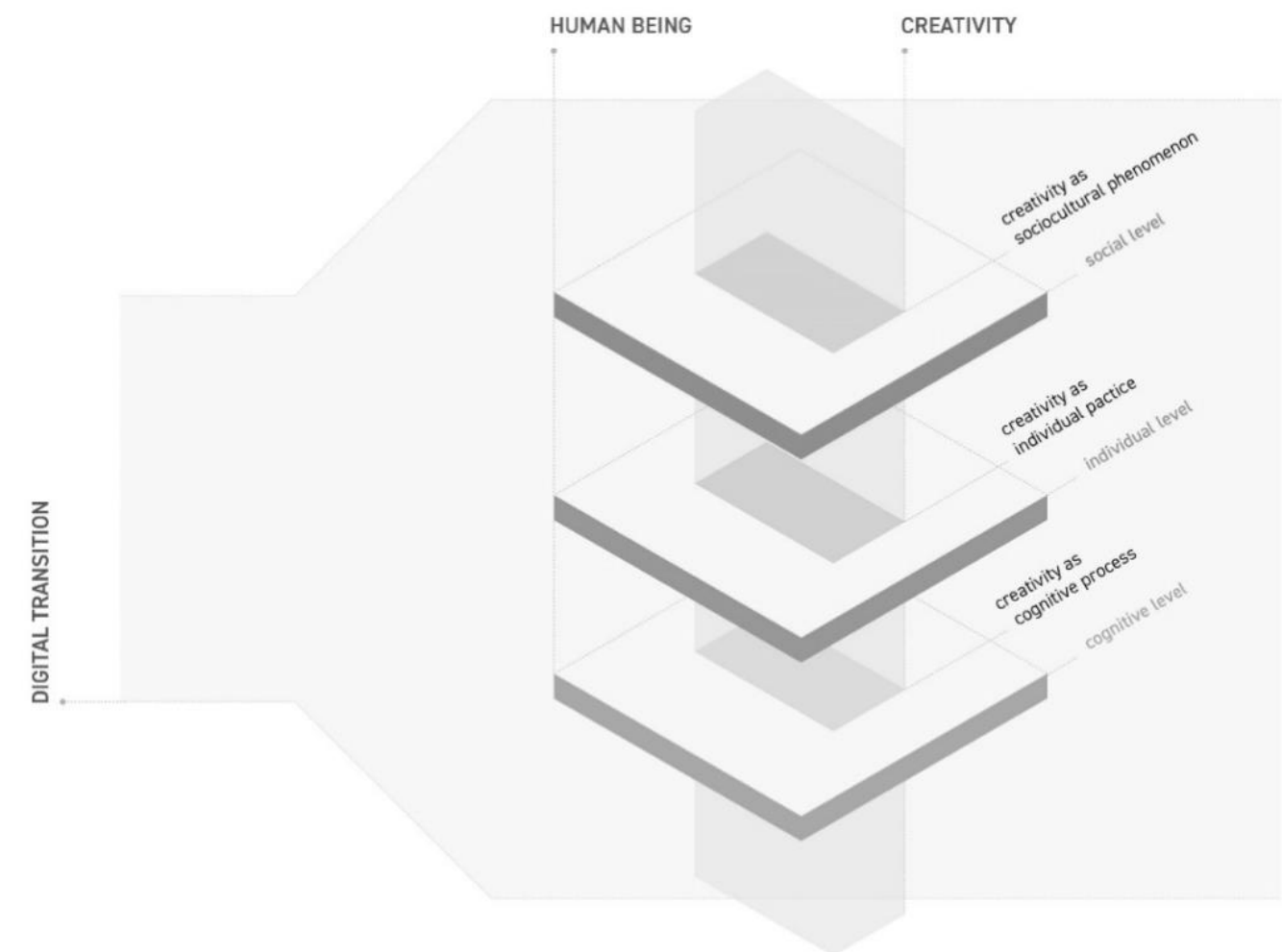

Figure 1. Representation of the Creativity 4.0 model

The Creativity 4.0 model, therefore, enables to explore how the concept of creativity is changing in the digital transition according to the levels mentioned above, which include:

- Creativity as a cognitive process that generates an outcome through multiple steps from information collection to the externalisation of the idea;

- Creativity as an individual practice requiring forms of bodily activity, things and tools, states of emotion and motivational knowledge; this involves intrapersonal competencies such as intrinsic motivation, self-management and self-discovery. 
- Creativity as a sociocultural phenomenon happening with others inside the society. This phenomenon is resulting from the interaction between people at different levels of skills and commitment, sharing resources and collaborating on projects, and encouraging a sense of creative agency and participation in the world; this involves interpersonal competencies such as communicating and collaborating, peer support, community engagement.

The model is the result of a deep work of reflections after the extensive literature investigation. It represents an exploratory model which allow identifying the criteria for the identification of the most crucial factors of creativity in the digital era. The criteria identified are:

- The digital transition is creating some inhibiting conditions for human creativity that could be possibly overcome by fostering some creativity factors. These are mainly related to the personal attitudes' factors;

- The new cultural, technological and social forces of the digital transition generate new factors of creativity which haven't been considered in the first selection. These are mainly related to the motivation and the socio-technical environment factors.

- The new cultural, technological and social forces of the digital transition could generate enabling or inhibiting conditions for some factors of creativity. These are mainly related to cognitive process and skills and technical skills factors.

It is not the intention of this paper to list all the factors identified within the research, but rather to show, in the next section, some reflections related to some changes that may be of interest for design education.

\section{UNDERSTANDING THE FACTORS THROUGH THE CREATIVITY 4.0 MODEL}

This section will highlight some cognitive, individual and social changes brought by the digital transition and their influence on some of the factors of creativity identified that are of major interest for the field of design education. For simplicity, the changes are described according to the three levels.

\subsection{Impact on the cognitive level}

Research in neuroscience has already started to investigate the impact of ICTs on human cognition, especially in terms of brain modification and changes in cognitive processes.

Empirical evidence about how the Internet environment have altered the cognitive behaviours and structures involved in information processing are shown in the literature [13].

One of the main causes of this alteration is due to the structure and nature of the online environment, considered as a global hypertext in which it is very simple to move from one page to another through "hyperlinks" resulting in a reduced learning effort that happens through quick scanning of information [13]. This could have a tremendous impact on the ability to process information deeply, reducing critical thinking of the information and memory consolidation. The reduction in long-term memory could have repercussions on the development of the individual culture, important for the quality and the originality of a project [14]. To overcome this situation, it becomes very fundamental to foster some factors of creativity, such as observation and intellectual curiosity, supporting the development of these personal attitudes' factors in the person through specific activities. This could allow overcoming the inhibiting conditions caused by the internet environment.

Beside this, the internet environment provides easy access to large amount of information, causing an information overload that blows up the divergent phase of the creative process, weakening the conceptual combination, a cognitive process factor of combining existing elements to generate a new idea that integrates previous ones or moves them in a novel direction [15].

\subsection{Impact on the individual level}

The democratisation of some digital technologies, such as 3D printing, laser cut machine, CNC machine and many others, is enabling new ways of engagement and participation for the individual, facilitating new forms of expression. Human beings today have access to sophisticated tools for rich media content creation, sharing of ideas, discussion, and distribution. This is opening a new dimension in which human being can self-discover its own creative attitude and express inner feelings, ideas, and visions, transforming and giving shape to whatever imagination can generate [16]. 
Self-expression and self-discover become therefore new crucial motivational factors in the digital era, factors capable of keeping high levels of engagement and participation throughout the whole creative process.

In order to master these technologies, new technical skills are required such as digital skills as well as a new set of soft skills collaboration and network building skills, verbal and visual communication abilities [17]. These competencies are needed to master more complex problem which requires to collaborate with other people and to face a continuous and ever-changing digital and social environment. Major digital transformations such as Artificial Intelligence (AI), machine learning, big data analytics, have big impacts on the creative process and can open opportunities for supporting the enhancement of some cognitive skill such as analogical thinking. Is this the case of IDEA-INSPIRE tool which is a computational tool that provides analogic stimuli relevant to the inserted input [18].

\subsection{Impact on the social level}

The widespread adoption of ICT technologies by a wider number of people has led to the creation of a hyperconnected society in which new social phenomenon, initiatives and communities (e.g., open source, peer-to-peer, etc.) are emerging with the aim of contributing to a more community-oriented society [19].

This hyper connection results also in the creation of new ways of collaborating on a wider scale, often at a global level, for shared purposes, such as the "creative communities", i.e., groups of people who cooperatively invent, enhance and manage innovative solutions, and therefore in the generation of an unprecedent number of ideas and projects, available for creative action and reaction.

This flourishing of ideas and projects enable an easily interaction with successful cases which produces a form of positive stimulation from a motivational point of view, therefore becoming an important factor of the socio-technical environment. This factor represents also an inspiration for the generation of new ideas and visions and an enabler of the conceptual combination factor. People create remixing ideas of others, working with tools made by others, and sharing their creative work with a wide and diversified audience.

In this scenario, new forms of collective exploration and evaluation are emerging that "shape the creative process by making it open to the views of others from early on, including during the process of making" [4]. These forms of collective feedback, defined as "distributed mentorship" by Campbell et al (2016) [20], in which each participant carry out both the generative and the evaluative function, are totally unique compared to the ones happening offline.

Community feedbacks have been recognised as a strong motivator to engage participants in the creative process providing a distributed socioemotional support for creators, therefore becoming a factor of the socio-technical environment

\section{REFLECTIONS AND FUTURE ACTIONS}

The paper discusses how the Creativity 4.0 model supports the identification of the most relevant factors of creativity in the digital age and the exploration of the opportunities that could enable or inhibit those factors. The model highlights how important is to foster some personal attitudes factors to overcome some inhibiting conditions brought by the digital transition. This transition is also creating new motivation for engagement and the requirement for new technical skills which can empower creativity. Moreover, the digital transition is creating conditions that could enable or inhibit some cognitive process and skills factors which are fundamental to analyse in relation to the creative design process. Some of these factors will be mapped on the different step of the process in order to identify the fundamental key points to support the new digitally enhanced generation to develop a creative approach appropriate to the transition in which they are living.

This information is fundamental for the design educators in order to train the next generation of designers empowering all stages of the design process to develop new and useful ideas and to master the changes brought by the digital transition.

For example, new active digital technologies, such as the generative design, support human being in generating multiple and unexpected solutions but requires a new kind of thinking and new skills. In this case, the designer fundamental role is to anticipate possible outcomes and to design the process to generate them through these technologies, collaborating with other stakeholders with diversified technical skills. 
For the design research has, therefore, become essential to understand the impact of digital technologies on the creative design process to update the conceptual toolbox; facilitate people creative potential to reach the best performance in each step of the process; address new technological challenges generating positive implications and large-scale innovation.

The ever-changing digital scenario will constantly require a deeper understanding of the technological, social and cultural opportunities that could enable or inhibit creativity. The Creativity 4.0 model could support this exploration even when the digital technology evolves because it represents the ground from which the model is feeding and that require continuous observation. The model enables the integration and interpretation of the most crucial factors of creativity in the digital transition, on the three human levels. Boundaries between such levels are often blurred and the allocation of the elements may be challenging. However, acknowledging their existence and close interaction, facilitates the comprehension of the complexity and multifarious aspects of both the human being and the creativity skill.

\section{REFERENCES}

[1] Prensky M.H. sapiens digital: From digital immigrants and digital natives to digital wisdom. Innovate: Journal of Online Education, vol. 5, 2009, pp. 1-9.

[2] Corazza G.E. Organic creativity for well-being in the post-information society. European Journal of Psychology, vol. 13, 2017, pp. 599-605.

[3] Amabile T.M. A Model of Creativity and Innovation in Organisations. Research in Organisational Behavior, vol. 10, 1988, pp. 123.

[4] Literat I. and Glaveanu V.P. Distributed Creativity on the Internet: A Theoretical Foundation for Online Creative Participation. International Journal of Communication, 2018, pp. 893-908.

[5] Manzini E. Design, when everybody designs : an introduction to design for social innovation, 2015 (The MIT Press)

[6] Sanders E. Scaffolds for building everyday creativity. In Design for Effective Communications: Creating Contexts for Clarity and Meaning, 2006, pp. 65-77 (Allworth Press, New York)

[7] Runco M.A. Comments on Where the Creativity Research Has Been and Where Is It Going. Journal of Creative Behaviour, vol. 51, 2014, pp. 308-313.

[8] Lubart T.I. Models of the Creative Process: Past, Present and Future. Creativity Research Journal, vol. 13, 2001, pp. 295-308.

[9] Sawyer R.K. Explaining creativity : the science of human innovation, 2012 (Oxford University Press)

[10] Amabile T.M. Componential Theory of Creativity. Harvard Business School, 2012, pp. 1-10.

[11] Roth B. Design Process and Creativity, 1973.

[12] Bruno C. and Canina M. Creativity 4.0. Empowering creative process for digitally enhanced people. In Proceedings of EAD2019 Conference, 10-12 ${ }^{\text {th }}$ April 2019, Dundee (under publication)

[13] Loh K.K. and Kanai R. How Has the Internet Reshaped Human Cognition?. Neuroscience, vol. 22, 2016, pp. 506-520.

[14] Tian M. et al. How does culture influence innovation? A systematic literature review. Article in Management Decision, 2018.

[15] Ward T.B. Creative Cognition, Conceptual Combination, and the Creative Writing of Stephen R. Donaldson, American Psychologist, vol 56, 2001, pp. 350-354.

[16] Zagalo N. Creativity in the Digital Age, 2015 (London: Springer-Verlag)

[17] Partnership for 21st Century Skills. 21st Century Skills, Education \& Competitiveness. A Resource and Policy Guide, 2008, p. 20.

[18] Chakrabarti A. et al. A functional representation for aiding biomimetic and artificial inspiration of new ideas. AI EDAM, vol. 19, 2005.

[19] Florida R. The rise of the Creative Class: And How It's Transforming Work, Leisure, Community and Everyday Life, 2003.

[20] Campbell J.A. Thousands of Positive Reviews: Distributed Mentoring in Online Fan Communities. In Proceedings of the 19th ACM Conference on Computer-Supported Cooperative Work \& Social Computing, 2016, pp. 691-704. 